\title{
Outer Wall of the Vestibule
}

National Cancer Institute

\section{Source}

National Cancer Institute. Outer Wall of the Vestibule. NCI Thesaurus. Code C33241.

The wall facing the outside of the vestibule of the inner ear. 